\section{Cerebral fat embolism in a non-head-injured trauma victim: A diagnostic dilemma}

Sir, Cerebral fat embolism (CFE) is a serious clinical disorder. Though rare, it has to be considered in trauma victims who develop an abrupt onset of neurological symptoms, which are not related to the initial insult. ${ }^{[1]}$ Interestingly, Eriksson et $a l^{[2]}$ noticed pulmonary fat embolism (PFE) in $82 \%$ of trauma victims and $63 \%$ of non-trauma cases, based on an autopsy series of 50 cases. Among their study group, only one developed CFE, indicating its rarity. Here, we report a case of CFE, following an uncomplicated femur fracture in order to recognize this entity on clinical grounds in resource limited settings.
A healthy 27 -year-old male was hit by a car on his left thigh and sustained a closed fracture midshaft of left femur. He was admitted in an orthopedic center, where he was fully conscious, well-oriented and hemodynamically stable with heart rate of $105 / \mathrm{min}$, supine blood pressure of $130 / 80 \mathrm{mmHg}$, respiratory rate of $19 / \mathrm{min}$, and room air saturation was $99 \%$. There was no other associated injury, and an injury severity score was 9. The fractured limb was splinted, and surgery was planned. After 12 hours of admission, he became restless, irritable and confused (GCS 10/15). Within 30 minutes of deterioration of his conscious level, he was referred to our hospital. On arrival, he was drowsy, localizing to deep painful stimuli and febrile. There was no circulatory instability or decrease in oxygen saturation. A non-contrast CT scan of the brain was inconspicuous. His hematology workup showed drop in platelet count and hemoglobin level, with an increased coagulation profile compared to his initial reports. There were no specific changes on electrocardiogram, chest x-ray and blood chemistry. CT scan of his chest did not show any evidence of pulmonary embolism. Venous duplex ultrasonography of the lower limbs was normal. A transthoracic echocardiogram did not reveal patent foramen ovale, elevated pulmonary artery pressure or any other abnormalities. As his sensorium continued to deteriorate, he was intubated and mechanically ventilated. Septic work-up for fever was not contributory. Arterial blood gas and fundoscopy was normal. There were no petechial or subconjuctival hemorrhage. Fat globules were not seen in the urine and sputum. Magnetic resonance imaging (MRI) of brain [Figure 1] showed scattered foci of hyperintensities on T2 weighted images in cerebral hemisphere, brain stem and cerebellum involving predominately white matter with areas of restricted diffusion consistent with CFE. His fracture was stabilized on day 4 under

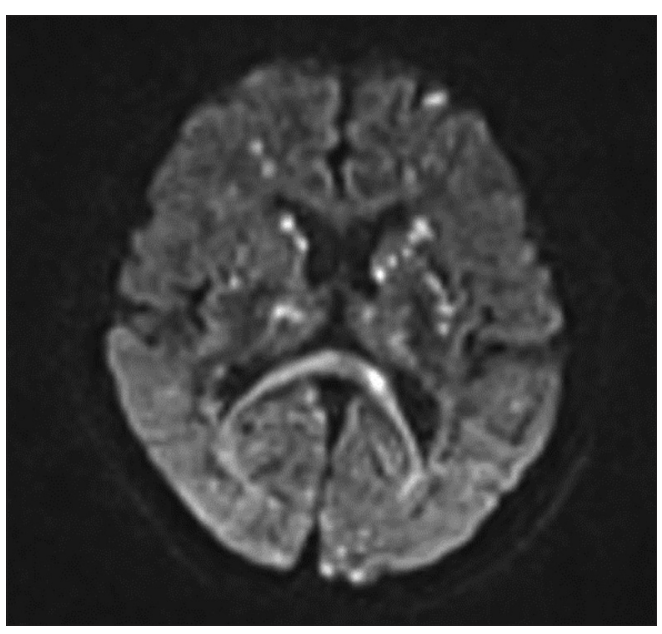

Figure 1: Diffusion-weighted images demonstrate multiple patchy hyper intense lesions in the bilateral cerebral hemispheres 
general anesthesia, followed by an extubation 24 hours thereafter and with supportive measures, he recovered uneventfully 10 days later.

The fat embolism syndrome, even today, possesses a diagnostic challenge to clinicians, as there are no standard criteria for the diagnosis. Interestingly, the diagnostic accuracy of the Gurd's criteria has been questioned already. The discrepancy among other diagnostic criteria makes CFE an unsettled mystery. Neurological symptoms are variable and non-specific and usually are in the form of a diffuse encephalopathy ${ }^{[3]}$ as noted in our case. In the literature, it is stated that neurological manifestation occurs after the development of the respiratory distress. However, this does not happen always as observed in our patient and reported by Gupta ${ }^{[4]}$ et al. In the absence of intracardiac shunt, an occurrence of CFE can be attributed to traverse of micro fat droplets through pulmonary circulation without sequestration, or a biochemical mechanism as reported. ${ }^{[5]} \mathrm{CT}$ brain findings though not contributory to the diagnosis of CFE, it rules out other causes of neurological dysfunction to some extent. For CFE diffusion-weighted, an MRI is more sensitive. Presence of a "starfield pattern" of scattered hyper intense lesions ${ }^{[6]}$ on long-TR images is characteristic of CFE as seen in our patient. Takahashi ${ }^{[7]}$ et al correlated CFE with the Glasgow Coma Scale and degree of clinical neurological impairment. Therefore, we conclude that in resource limited environ, the possibility of CFE may be invoked, especially in any non-head-injured trauma patients who is initially lucid and subsequently deteriorate in their sensorium in the absence of any other demonstrable causes for altered sensorium, and patient be referred to higher center for further evaluation / confirmation if the condition of the patient is permissible.

\section{Acknowledgments}

Dr. K. Arthanari, M.S for his logistical support

Subramanian SenthilKumaran, N Balamurugan ${ }^{1}$, P Suresh, P Thirumalaikolundusubramanian ${ }^{2}$

Departments of Emergency and Critical Care Medicine, and ${ }^{1}$ Neurosciences, Sri Gokulam Hospital and Research Institute, Salem, ${ }^{2}$ Chennai Medical College Hospital and Research Centre, Irungalur, Trichy, India

Address for correspondence: Dr. S. SenthilKumaran,

Department of Accident, Emergency and Critical Care Medicine, Sri Gokulam hospitaland Research institute, Salem, Tamil Nadu, India. E-mail: maniansenthil@yahoo.co.in

\section{References}

1. Gregorakos L, Sakayianni K, Hroni D, Harizopoulou V, Markou N, Georgiadou F, et al. Prolonged coma due to cerebral fat embolism: Report of two cases. J Accid Emerg Med 2000;17:144-6.

2. Eriksson EA, Pellegrini DC, Vanderkolk WE, Minshall CT, Fakhry SM, Cohle SD. Incidence of pulmonary fat embolism at autopsy: An undiagnosed epidemic. J Trauma 2011;71:312-5.

3. Scopa M, Magatti M, Rossito P. Neurologic symptoms in fat embolism syndrome: Case report J J Trauma 1994;36:906-8.

4. Gupta B, Kaur M, D'souza N, Dey CK, Shende S, Kumar A, et al. Cerebral fat embolism: A diagnostic challenge. Saudi J Anaesth 2011;5:348-52

5. Eriksson EA, Schultz SE, Cohle SD, Post KW. Cerebral fat embolism without intracardiac shunt: A novel presentation. J Emerg Trauma Shock 2011;4:309-12.

6. Parizel PM, Demey HE, Veeckmans G, Verstreken F, Cras P, Jorens PG, et al. Early diagnosis of cerebral fat embolism syndrome by diffusionweighted MRI (starfield pattern). Stroke 2001;32:2942-4.

7. Takahashi M, Suzuki R, Osakabe Y, Asai JI, Miyo T, Nagashima G, et al. Magnetic resonance imaging findings in cerebral fat embolism: Correlation with clinical manifestations. J Trauma 1999;46:324-7.

\begin{tabular}{|l|l|}
\hline \multicolumn{2}{|c|}{ Access this article online } \\
\hline Quick Response Code: & Website: \\
\hline & www.ruralneuropractice.com \\
\cline { 2 - 2 } & \\
\hline
\end{tabular}

